\title{
Experiment of Hydatid Cyst in Two Strains (Camels and Goats) in Saudi Arabia
}

\author{
Areej O. Bakhraibah, Muslimah N. Alsulami, Fawzia H. Toulah, Amal A. El Shafi \\ Department of Biology, Faculty of Science, University of Jeddah, Saudi Arabia \\ Email: Dr.abakhraibah@gmail.com
}

How to cite this paper: Bakhraibah, A.O., Alsulami, M.N., Toulah, F.H. and El Shafi, A.A. (2019) Experiment of Hydatid Cyst in Two Strains (Camels and Goats) in Saudi Arabia. Open Journal of Animal Sciences, 9, 76-87.

https://doi.org/10.4236/ojas.2019.91007

Received: November 6, 2018

Accepted: January 7, 2019

Published: January 10, 2019

Copyright $\odot 2019$ by authors and Scientific Research Publishing Inc. This work is licensed under the Creative Commons Attribution International License (CC BY 4.0).

http://creativecommons.org/licenses/by/4.0/

\begin{abstract}
Hydatid cyst disease is one of the most parasitic diseases transmitted from carnivores animals (such as dogs) to humans and causes a deterioration in the general health. Its transmission to herbivores animals led to a substantial economic loss in the meat productivity and reduced its quality. The increase of acquisition of dogs at homes nowadays led to an increase in the risk of infection with many parasitic diseases such as hydatid cyst disease. The present study was conducted to provide a modern view on the current status of hydatid cyst disease among slaughtered animals in Jeddah through periodic visiting to a slaughter house in North Jeddah. The mice prepared have been infected in the peritoneal membrane with $0.2 \mathrm{ml}$ of hydatid cyst fluid containing \pm 2000 protoscoleces from fertile cysts obtained from an infected goat's liver which resulted in a $75 \%$ infection rate. Mice infected with hydatid fluid from fertile cysts obtained from an infected camel's lungs showed a result of $11.1 \%$ infection rate. The cysts appeared in the peritoneal and abdominal cavity.
\end{abstract}

\section{Keywords}

E. granulosus, Swiss Albino Mice, Protoscoleces, Hydatid Cyst Disease, Hydatid Cysts, Virulence of Scoleces

\section{Introduction}

Since the existence of humans and feeding has been one of the main survival instincts, by primitiveness, we learned to benefit from animals and raise them in a general way as well as benefit from their meat in specific ways [1] [2].

Along with the increase of the population in the Kingdom of Saudi Arabia, there has been an increase in the need of animal based food products. Thus, the goal has shifted into protecting the animal revolution which itself needs veterinary 
protection especially that such animals are prone to getting infected with many diseases such as bacteria and viruses (viral) or parasites [1].

A number of parasites are transmitted from animal to animal or from animal to humans and that's a catastrophe itself, especially with the lack of health education amongst some people. Moreover, not paying enough attention to the veterinary services on a better level aids such parasitic diseases to spread resulting global health issues [3].

One of the most important and our subject of research is Hydatid cyst disease. It is considered one of the most important and dangerous parasitic diseases that spread from carnivorous (meat eating) animals, like dogs, to humans causing a deterioration in human's health conditions. As well as transmit to plant eating animals such as camels, cows, sheep and goats. Therefore, that is a major economical loss in the meat production industry and causes a decrease in the meat's quality and nutritional value [4].

The infection takes place when the ova of Cestoda (Echinococcus sp.) that lives in the small intestines of carnivorous animals (such as dogs) is ingested. Another effective method of infection is the direct contact with animals infected or the ingestion of raw vegetables or fruits that are contaminated with the ova of the Cestoda. These ova hatch after humans or animals ingest it and the embryos are released, they then penetrate the small intestine's wall and make their way to the blood flow. The blood flow transmits them to different organs in the body such as the kidneys, lungs, brain, liver, muscles and others organs, where they form what is known as Hydatid cyst, causing Hydatid cyst disease (Hydatidoses).

The illness might host the human body for a long time (10 - 20 years) without the appearance of any symptoms. When there is an increase in the amount of Hydatid cysts or their size symptoms arise, which differentiate from an infected organ to other. Symptoms such as difficulty in respiration and lungs inflammation occur if the lungs are the organ infected; Disruption in digestion and meteorism if found in the liver; severe pains in the stomach if found in the intestines; neurological symptoms and seizures in cases of hydatid cyst affecting any vital centers in the brain and anaphylactic shock in case of the explosion of the hydatid cyst which is considered fatal [5] [6].

The prevalence of hydatid cyst infections are international, especially in places where direct contact between the final host and the infected cattle is common like Central America, Central Sea Beaches, The Middle East, Southeast Asia, North Africa, Uganda, Kenia, New Zealand, Europe and China [6] [7].

In Saudi Arabia, there have been some studies about the extent of hydatid cyst disease and its expansion between the local and imported cattle as well as humans. In Jeddah, Toulah et al. [2] reported the infection rate of hydatid cyst disease in internationally imported animals was $0.42 \%$. In addition, they found that the highest prevalence of infection was in cattle representing $0.60 \%$. Baeshen [8] announced that the percentage of infection has reached $7.55 \%$ and $0.67 \%$ in local and imported animals respectively. Malaika et al. [9] presented overall studies on 188 patients from different hospitals in the KSA, his results confirmed that the 
highest rate of infection recorded was in patients of the Southwest region followed by the Central region.

Diagnosis of the hydatid cyst disease is based on an inspection of slaughtered animals or post death anatomy in the traditional ways and by a histological examination to those larvae microscopically to distinguish between them and other Cestoda larvae. As for human beings, the diagnosis is made through X ray scans and ultrasonic waves or through inspections of the cysts that is acquired after a complete surgical removal of them and performing a histological examination looking for the presence of antibodies in the cyst in the patient's serum [10].

To this day, the only treatment for humans is the surgical removal of those hydatid cysts cautiously to prevent the spillage of the contents if the hydatid cyst is punctured [11]. About the effectiveness of the chemical treatment Ceballos et al. [12] has reported the result of using the drug albendazole for a long period of time and has pointed out its inability of getting absorbed well and to the decrease in its ability to pass through the hydatid cyst's wall. Khanfar [5] has pointed out that if the drug Albendazole is being used with the drug Paraziquntel it gives out good results.

Therefore, the current study aims to infect a number of mice with a hydatid cysts fluid extracted from two different kinds of infected animals to recognize the effectiveness of each on infecting.

\section{Materials and Methods}

A study on the effectiveness of virulence of scoleces in creating experimental infection is presented.

\subsection{Virulence of Scoleces}

\subsubsection{Preparation of the Sources of Infection}

Numerous samples of the hydatid cyst fluid have been extracted from hydatid cysts of camels and goats severally. The scoleces have been counted microscopically and a dose has been prepared according to Aboul-Atta et al. [13] where a $0.5 \mathrm{ml}$ of fluid contained \pm 2000 of the scoleces that has been treated before usage by adding 100 units of penicillin with $200 \mathrm{ml} / \mathrm{kg}$ of streptomycin according to Kakru et al. [14].

\subsubsection{Inspection, Division and Preparation of the Experimental Mice}

This experiment has been conducted on 60 Swiss Albino mice that were aged 3 weeks (post weaning period) and that were free of any parasitic infections. They have been collected from an animal house in King Fahad's center in King Abdul Aziz University, Jeddah. Used for their care were plastic cages that a standard experiment's fodder has been added to from King Fahad's center, and have been placed under suitable health conditions for 12 months.

- The mice groups have been randomly divided into 2 groups with 30 mouse in each:

Group 1: each mouse was infected by getting injected in the peritoneal mem- 
brane (with a $1 \mathrm{ml}$ needle attached to an inner $10 \mathrm{ml}$ injector) with the previously mentioned dose of the hydatid cyst fluid that has been extracted from the hydatid cyst of an infected goat's liver.

Group 2: each mouse has been infected in the peritoneal membrane with the previously mentioned dose of the hydatid cyst fluid that has been extracted from hydatid cysts of an infected camel's lungs.

\subsection{Study Program}

The experiment's mice have been inspected monthly for a span of 12 months following their health conditions regarding activity, mobility and any presence of meteorism in the stomach. 2 - 3 mice have been randomly chosen from the infected mice prepared along with the most sick out of each group every month until the experiment came to end. They have been drugged by Ether and had their abdominal cavity and ribcage opened and inspected carefully via the naked eye and by the aid of a manual lens to look for any Hydatid cysts. The skulls have been opened as well and the brain and eyes were extracted for inspection.

\section{Results}

\section{Scoleces Ability to Infect}

Group one: 30 mice had been infected with hydatid cyst fluid that has been extracted from cysts in the goat's liver. The results have shown deterioration in the health of these mice around the second month of infection with the observation of stomach meteorism (Figure 1) especially in the last month of the experiment. 2 - 3 mice have been chosen every month to inspect any presence of hydatid cysts until the $8^{\text {th }}$ month of infection where the remaining mice died, which has been counted 10 mice. With the eye inspection and the aid of a manual lens, no hydatid cyst has been found in the chest cavity and brain to the end of the experiment (Figure 2, Figure 3). Hydatid cysts have been found in the abdominal cavity two months after the infection, it was small in size but clearly present and in various numbers to where the percentage of inspection has been recorded $75 \%(15 / 20)$ in the mice post anatomy (Figures 4-7).

As for Group 2, where the mice (30) were infected via the hydatid cyst fluid extracted from cysts in the camel's lungsthe results that have shown that most

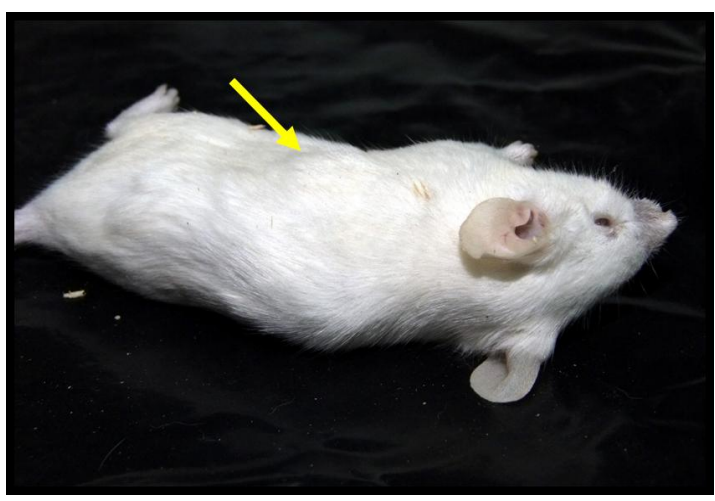




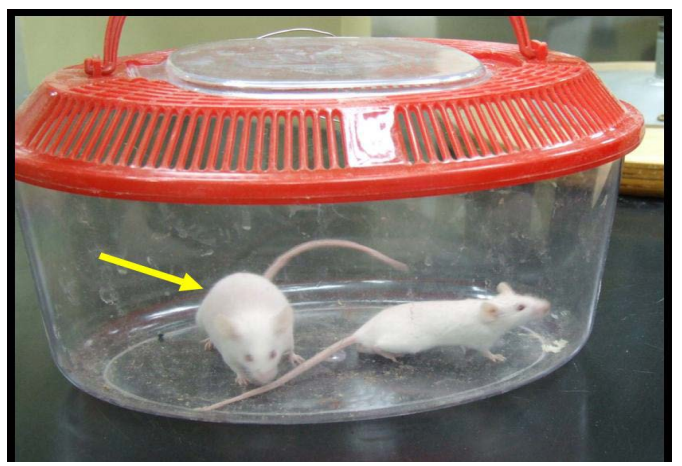

Figure 1. A mouse with meteorism.

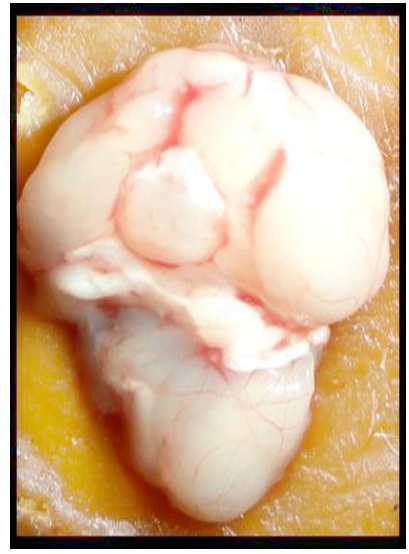

Figure 2. A mouse's brain free of any hydatid cyst.

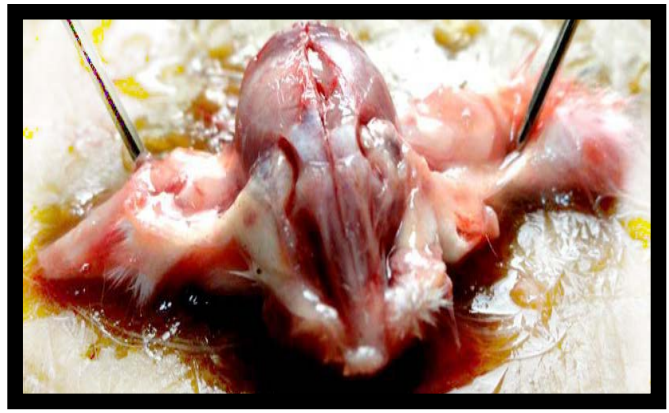

Figure 3. A mouse's brain free of any hydatid cyst.

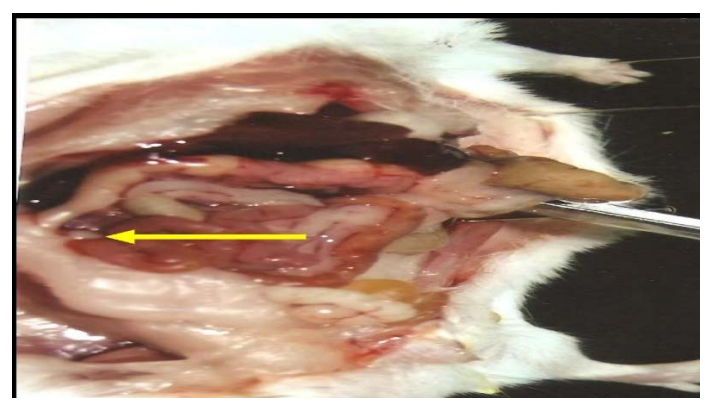

Figure 4. A mouse after an autopsy 2 months after it has been infected in the peritoneal membrane with the hydatid cyst fluid obtained from cysts in the goat's liver. The arrow shows a hydatid cysts attached to the intestines. 


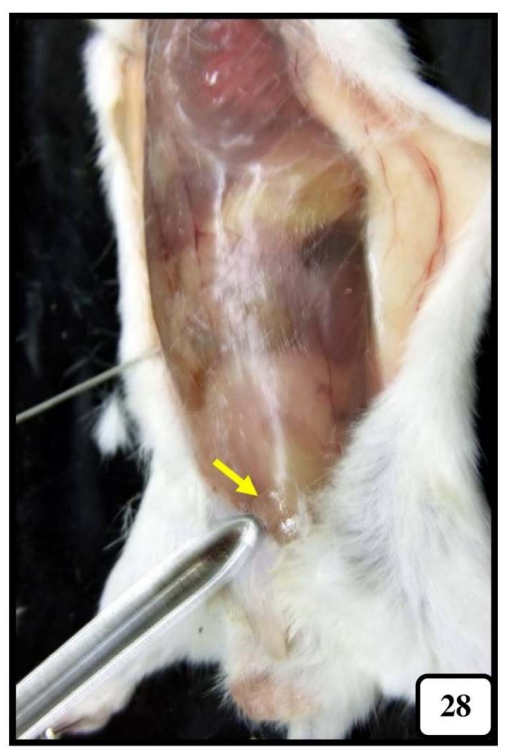

Figure 5. A mouse that has been diagnosed 4 months after its infection in the peritoneal membrane with a hydatid cyst fluid that has been obtained from cysts extracted from a goat's liver. The arrow shows the presence of hydatid cysts attached to the abdominal wall and that is due to the leakage of a drop from the hydatid cyst fluid during the process of injection inside the stomach.

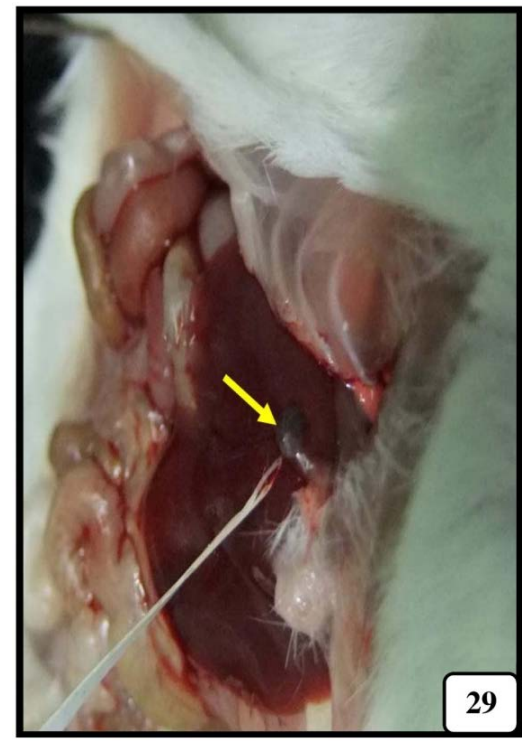

Figure 6. A mouse after its anatomy after 5 months from getting infected in the peritoneal membrane with a hydatid cyst fluid that has been obtained from cysts in the goat's liver. The arrow shows the presence of a cyst attached to the liver.

mice were in good health conditions until the end of the experiment (12 months). When inspecting 2 - 3 of the mice prepared each month until the end of the experiment, cysts appeared in the abdominal cavity in only 3 mice from the mice prepared and that was on the $5^{\text {th }}, 7^{\text {th }}$ and $8^{\text {th }}$ month of the infection, which estimates to $11.1 \%(3 / 27)$ and only 3 mice were recorded dead during the experiments time. The sizes of the cysts discovered in the mice were smaller in size 


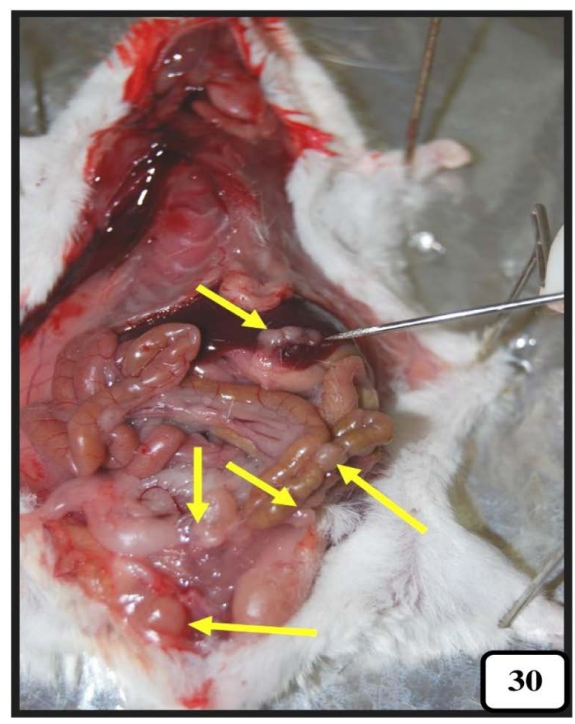

Figure 7. A mouse after anatomy that has been diagnosed 6 months after being infected in the peritoneal membrane with a hydatid cyst fluid that has been obtained from cysts in a goat's liver. The arrow shows 3 cysts attached to the liver and two cysts to the intestines.

when compared with the cysts obtained from the mice infected by hydatid cyst fluid from an infected goat's liver.

Viciousness has been observed amongst both groups in the primary months of the experiment a long with hyperactivity, although, towards the end of the experiment the hyperactivity decreased in both groups.

\section{Discussion}

This experiment has been conducted on 60 Swiss Albino mice that are three weeks old and have been divided into two separate groups. Group 1 was injected in the peritoneal membrane with a hydatid cyst fluid obtained from cysts present in an infected goat's liver. As for group 2, it got injected in the peritoneal membrane with hydatid cyst fluid obtained from cysts present in an infected camel's lungs. The rate of the parasitic growth is determined based on many factors which include the scoleces according to what Mousavi \& Tappah [15] mentioned. In this study, two sources have been chosen to collect scoleces (camels and goats) based on the fact that they are of different strains. Rad et al. [16] declared that the camel strains were found in camels which have been infected and not in any other average hosts. Yang et al. [17] classified that the sheep strain of the E. granulosus worm is present in the goats and cows, sheep, bulls and humans.

Janssen et al. [18] pointed out there are many ways to find out the variations or subspecies of the E. granulosus worm like the morphological comparisons [19] that developed in vivo such as the infection with the secondary cysts in the experiment's mice [20], and that developed in vitro [21] caused a cross infection in different intermediate hosts [22] and bio chemical differences as well [23].

The method of injecting the experimental animals with protoscoleces to ob- 
tain the hydatid cyst was according to what Sarimehmetoglu et al. [24] clarified, where he mentioned that infecting the mice in this way is considered safe and less dangerous than using the worm's ovum. It is also an easy and cheap way and allows the researchers to work with a huge number on animals.

These protoscoleces are the advanced infectious parasite of E. granulosus in the final host (dogs) but these scoleces are capable of differentiation and asexual reproduction into secondary cysts. This happens after there has been an explosion of the primary cysts and an escape and dispersal of these scoleces inside an intermediate host [25].

Mice have been infected with a dose of \pm 2000 virulence of scoleces where Kakru et al. [14] proved that injecting 40 mice in the peritoneal membrane with the number of 2000 of scoleces from the hydatid cysts fluid (that has been surgically removed from an infected being) caused $80 \%$ of infection, forming cysts that go between $1-2 \mathrm{ml}$ in diameter in the span of $2-3$ months in the mice. He also noticed meteorism in the stomach after 6 - 7 months then the death of all mice. However, when injecting the mice with 1000 scoleces, they didn't form any cysts within them.

Mousavi \& Tappeh [15] proved that when using different doses of 500, 1000, 2000 of the virulence of scoleces in $0.5 \mathrm{ml}$ of a physiological solution and injecting it in the peritoneal membrane of the experiments mice (Ballb/c), the 2000 dosage was the best where hydatid cysts appeared in places such as the liver, and peritoneal membrane to the highest number of infected mice. Opposing to that, some studies showed that dosages less that 2000 protoscoleces have been used and were successful in causing an infection. As Breijo et al. [26] infected the experimental mice with almost 1000 protoscoleces in $0.2 \mathrm{ml}$ of physiological solution and after a month of infection cysts has been found with the size $0.5-0.75$ $\mathrm{ml}$.

Results have shown that the current study in Group 1 has shown a deterioration in the health conditions of the mice where 30 mouse was infected with hydatid cysts fluid obtained from an infected goat's liver since the second month of infection, along with the appearance of meteorism especially in the last months of the infection, therefore 10 mice died in the $8^{\text {th }}$ month of the experiment. With naked eye inspection and help of a manual lens, 2 - 3 mice has been inspected each month and no hydatid cysts have been found in the chest cavity and brain till the end of the experiment. Although, the hydatid cysts have appeared in the abdominal cavity two months after the infection, their sizes were small but was clearly found and in different sizes causing the infection's rate among the mice to reach $75 \%(15 / 20)$.

As for group 2 that had 30 mice infected with a hydatid cyst fluid extracted from the lungs of a camel, the results clarified that most mice were in good health conditions until the end of the experiment (12 months), despite the death of 3 mice. When inspecting the 2 - 3 infected mice monthly, hydatid cysts appeared in the abdominal cavity of only 3 mice $(3 / 27)$ by the 5 th, 7 th and 8 th month of infection, with that we record the rate of infection reaching $11.1 \%$. 
The results clarified that only a small percentage of scoleces that has been injected caused cysts. Therefore, Zhang et al. [27] clarified that most scoleces are killed by the host.

Our study's results agree with Rogan \& Richards [28] who found that only $1 \%-3 \%$ of the scoleces that has been injected in mice $( \pm 3000)$ caused secondary cysts.

Other studies in vivo and in vitro handled this side like that Aboul-Atta et al. [13] held, where he infected 20 mice with hydatid cyst fluid extracted from a goat's liver and 20 other mice infected with hydatid cyst fluid extracted from an infected camel's lungs, this experiment was conducted for 12 months. He noticed the appearance of some cysts after 2 and half months of infection in group one. Their sizes went between $1-2 \mathrm{ml}$ then increased in number and size where the infection rate reached $85 \%$. As for the second group, the cysts appeared during the $9^{\text {th }}$ month of infection and reached the percentage of $10 \%$.

Our study's results agreed with the study that has been conducted by McManus et al. [29] that a human is a refractory host or has a low chance of getting infected with the camel's strain of the E. granulosus worm. He agreed with Wachira et al. [30] where he clarified that despite the contact between humans and an infected dog from camels and goats strain there is still no reports that prove of humans getting infected from camels strain. He added as well that a lot of experimental results proved that the most infectious worms of E. granulosus that infect humans are of the goats strain. Eckert \& Thompson [31] also declared that the sheep, cows and the white deer of E. granulosus worm is infectious to humans while horse strains, pigs and camels are less infectious or not infectious at all.

Hokelek et al. [32] injected 12 mice in the peritoneal membrane with a dose of $0.1 \mathrm{ml}$ from the protoscoleces solution, the mice were dissected 3 months after the infection and hydatid cysts have been found with a $3 \mathrm{ml}$ diameter in size.

Mousavi \& Tappeh [15] infected 39 mice in the peritoneal membrane with a dose of 2000 of the scoleces that has been obtained from hydatid cysts in the liver and lungs of infected goats, thus, within 20 weeks from the infection 8 mice were found dead. After 5 months of the infection, the mice were inspected to search for any hydatid cysts causing the infection's rate to reach $18.8 \%(6 / 31)$ and cysts has been found in the liver and peritoneal membrane that vary in sizes between $0.3-2 \mathrm{ml}$.

In addition, Andrew et al. [33] studied the in vitro and a number of scoleces that has been obtained from cow's liver and from livers and lungs of sheep and livers of horses where he found obvious differences in the immunity's affect. He added that these differences were due to many factors, one of them being the type of animal and the type of organ, in addition to the period of time those scoleces existed in the external media, along with the variation in the genetic conditions and the physiological conditions to the infection's source.

As for Casado et al. [34] in their in vitro study, he found that there were no meaningful difference in the survival time of the scoleces extracted from the liver 
and lungs of sheep and the liver of a horse in several medias.

\section{Conclusion}

The intensity of the hydatid cyst disease is increasing which calls for strict laws from the Jeddah province to overcome the prevalence of this disease. Studies on strain variability must be done as it has an important role in putting new programs of prevention and control of the disease. Periodic studies of the disease should be held to study the rate at which the disease is spreading. This issue calls for veterinary control as well as public awareness to eliminate this issue in a short period of time.

\section{Conflicts of Interest}

The authors declare no conflicts of interest regarding the publication of this paper.

\section{References}

[1] Fasl-deen, Y.A.M. (2007) Epidemiological and Histopathological Studies on the Prevalence of Echinococcosis in Cattle in Medina. M.Sc. Thesis, King Abdul Aziz University, Jeddah.

[2] Toulah, F.H., El Shafi, A.A., Alsolami, M.N. and Wakid, M.H. (2017) Hydatidosis among Imported Animals in Jeddah, Saudi Arabia. Journal of Liver and Clinical Research, 4, 1031.

[3] Moro, P. and Schantz, P.M. (2008) Echinococcosis: A Review. International Journal of Infectious Diseases, 13, 125-133. https://doi.org/10.1016/j.ijid.2008.03.037

[4] Carabin, H., Budke, C.M., Cowan, L.D., Willingham, A.L. and Torgerson, P.R. (2005) Methods for Assessing the Burden of Parasitic Zoonoses: Echinococcosis and Cysticercosis. Trends in Parasitology, 12, 327-333. https://doi.org/10.1016/j.pt.2005.05.009

[5] Khanfar, N. (2004) Hydatid Disease. A Review and Update. Current Anaesthesia \& Critica, 15, 173-183. https://doi.org/10.1016/j.cacc.2004.06.002

[6] Tsang, K. and File, T. (2008) Respiratory Infections Unique to Asia. Respirology, 13, 937-949.

[7] Li, T., Ita, A., Nazuhiro, K., Qiu, J., Nakao, M., Zhen, R., Xiao, N., Chen, X., Giraudoux, P. and Craig, P.S. (2008) Species Identification of Human Echinococcosis Using Histopathology and Genotyping. Transactions of the Royal Society of Tropical Medicine and Hygiene, 102, 585-590. https://doi.org/10.1016/j.trstmh.2008.02.019

[8] Baeshen, M.N. (1998) Epidemiological and Histopathological Studies on the Prevalence of Echinococcosis in Camels in Jeddah, M.Sc. Thesis, King Abdul Aziz University, Jeddah.

[9] Malaika, S.S., Attayeb, A., Sulaimani, S. and Reddy, J.J. (1981) Human Echinococcus in Saudi Arabia. Saudi Medical Journal, 2, 77-85.

[10] Sarisoy, H.T., Memisoglu, K., Tamer, G.S. and Sarlak, A.Y. (2008) Primary Hydatid Disease in Adductor Muscles. Clinical and Investigative Medicine, 31, 296-299. https://doi.org/10.25011/cim.v31i5.4877

[11] Brahim, B., Nouri, A., Ksia, A., ElEzzi, O., Krichene, I., Mekkim, M. and Belghith, 
M. (2008) Management of Multiple Echinococcosis in Childhood with Albendazole and Surgery. Journal of Pediatric Surgery, 43, 2024-2030. https://doi.org/10.1016/j.jpedsurg.2008.04.024

[12] Ceballos, L., Elissondo, C., Moreno, L., Dopchiz, M., Bruni, S., Denegri, G., Alvarez, L. and Lanusse, C. (2008) Albendazole Treatment in Cystic Echinococcosis: Pharmacokinetics and Clinical Efficacy of Two Different Aqueous Formulations. Parasitology Research, 103, 355-362. https://doi.org/10.1007/s00436-008-0980-x

[13] Aboul-Atta, A.M., Ibrahim, S.A., Nagui, A.M. and Abd Rabo, M.A. (1998) Experimental Secondary Echinococcosis of Two Strains of E. granulosus. A Parasitological Study in Immunosuppressed Mice. J. Hepatolo. Gastroenterol \& Infectious Diseases, 5, 35-44.

[14] Kakru, D.K., Sofi, B.A. and Assadullah, S. (2008) Novel Route of Infection in Experimental Model of Hydatid Disease. Indian Journal of Pathology and Microbiology, 51, 373-375. https://doi.org/10.4103/0377-4929.42514

[15] Mousavi, J. and Tappeh, K.H. (2010) Production of Experimental Hydatid Cysts in the Eye, Peritoneum and Liver of BALB/c Mice. Turkiye Parasitologi Dergisi, 34, 21-23.

[16] Rad, S.M., Filisetti, D., Oudni, M., Mekki, M., Belguith, M., Nouri, A., Sayadi, T., Lahmar, S., Candolfi, R., Azaiez, H., Mezhoud, H. and Babba, H. (2005) Molecular Evidence of Ovine (G1) and Camel (G6) Strains of Echinococcus granulosus in Tunisia and Putative Role of Cattle in Human Contamination. Veterinary Parasitolo$g y$, 129, 267-272. https://doi.org/10.1016/j.vetpar.2005.02.006

[17] Yang, Y.R., Rosenzvit, M.C., Zhang, L.H., Zhang, J.Z. and McManus, D.P. (2005) Molecular Study of Echinococcus in West-Central China. Parasitology, 131, 547-455. https://doi.org/10.1017/S0031182005007973

[18] Janssen, D., Wit, M. and Rycke, P.H. (1990) Hydatidosis in Belgium: Analysis of Larval Echinococcus granulosus by Sds-Page and Western Blotting. Annales de la Société Belge de Médecine Tropicale, 70, 121-129.

[19] Thompson, R.C.A. (1977) Growth, Segmentation and Maturation of the British Horse and Sheep Strains of E. granulosus in Dogs. International Journal for Parasitology, 7, 281-285. https://doi.org/10.1016/0020-7519(77)90036-4

[20] Kurnaratilake, L.M. and Thompson, P.C.R. (1983 ) A Comparison of E. granulosus from Different Geographical Areas of Australia Using Secondary Cyst Development in Mice. International Journal for Parasitology, 13, 509-515. https://doi.org/10.1016/S0020-7519(83)80016-2

[21] Smyth, J.D. and Davies, Z. (1974) Occurrence of Physiological Strains of Echinococcus granulosus Demonstrated by in Vitro Culture of Protoscoleces from Sheep and Horse Hydatid Cysts. International Journal for Parasitology, 4, 443-445. https://doi.org/10.1016/0020-7519(74)90057-5

[22] Dada, B.J.O., Belina, E.D., Adagboye, D.S. and Mohammed, A.N. (1981) Experimental Transmission of E. granulosus of Camel/Dog Origin to Goats, Sheep, Cattle and Donkeys. International Journal of Zoonoses, 8, 33-43.

[23] McManus, D.P. and Barrett, N.J. (1985) Isolation, Fractionation and Partial Characterization of the Tegumental Surface from Protoscoleces of the Hydatid Organism, Echinococcus granulosus. Parasitology, 90, 111-129. https://doi.org/10.1017/S0031182000049064

[24] Sarimehmetoglu, O., Bumin, A. and Gonenc, B. (2004) Diagnosis of Secondary Hydatid Cysts in White Mice by Ultrasonography and Doppler Examination. Revue de Médecine Vétérinaire, 155, 587-590. 
[25] Thompson, R.C.A., Lymbery, A.J. and Constantine, C.C. (1995) Variation in Echinococcus. Towards a Taxaonomic Revision of the Genus. Advances in Parasitology, 35, 145-176. https://doi.org/10.1016/S0065-308X(08)60071-8

[26] Breijo, M., Spinelli, P., Sim, R.B. and Ferreira, A.M. (1988) Echinococcus granulosus. An Intraperitoneal Diffusion Chamber Model of Secondary Infection in Mice. Experimental Parasitology, 90, 270-276.

[27] Zhang, W.B., Jones, M.K., Li, J. and McManus, D.P. (2005) Echinococcus granulosus. Pre-Culture of Protoscoleces in Vitro Significantly Increases Development and Viability of Secondary Hydatid Cysts in Mice. Experimental Parasitology, 110, 88-90. https://doi.org/10.1016/j.exppara.2005.02.003

[28] Rogan, M. and Richards, K.S. (1986) Echinococcus granulosus: In Vivo Effect of Monensin on the Tegument of the Protoscolex. Parasitology, 93, 347-355. https://doi.org/10.1017/S0031182000051519

[29] McManus, D.P., Thompson, R.C.A. and Lymery, A.J. (1989) Comment on the Status of Echinococcus granulosus in the UK. Parasitology Today, 5, 365-367. https://doi.org/10.1016/0169-4758(89)90114-2

[30] Wachira, T.M., Bowles, J., Zeyhle, E., et al. (1993) Molecular Examination of the Sympatry and Distribution of Sheep and Camel Strains of Echinococcus granulosus in Kenya. The American Journal of Tropical Medicine and Hygiene, 48, 473-479. https://doi.org/10.4269/ajtmh.1993.48.473

[31] Eckert, J. and Thompson, R.C. (1997) Intraspecific Variation of Echinococcus granulosus and Related Species with Emphasis on Their Infectivity to Humans. Acta Tropica, 64, 19-34. https://doi.org/10.1016/S0001-706X(96)00635-3

[32] Hokelek, M., Erzurumlu, K., Uyar, Y. and Guvenli, A. (2001) Comparison of Two Methods of Experimental Cystic Echinococcosis in Balb/C Mice. Türkiye Parazitoloji Dergisi, 25, 142-144.

[33] Macintyre, A.R. and Dixon, J.B. (2001) Echinococcus granulosus. Regulation of Leukocyte Growth by Living Protoscoleces from Horses, Sheep and Cattle. Experimental Parasitology, 99, 198-205. https://doi.org/10.1006/expr.2001.4662

[34] Casado, N., Rodriguez-Caabeiro, F. and Hernandez, S. (1986) In Vitro Survival of Echinococcus granulosus Protoscoleces in Several Media, at $+4^{\circ} \mathrm{C}$ and $+37^{\circ} \mathrm{C} \mathrm{Z}$. Parasitenkd, 72, 273-278. https://doi.org/10.1007/BF00931155 